\title{
Primary and Secondary Prevention of Cervical Cancer at Two Dis- trict Health Centres in the West Region of Cameroon
}

\author{
Tagne Simo Richard ${ }^{1 *}$, Christian Kamnang Tchakounte ${ }^{2}$, Léonie Marthe Ghomsi Sidje ${ }^{2}$, Jacqueline \\ Ferrand $^{2}$, Armel Hervé Nwabo Kamdje ${ }^{1}$, Paul F Seke Etet ${ }^{3,4}$ and Phelix Bruno Telefo ${ }^{5}$
}

\author{
${ }^{1}$ Department of Biomedical Sciences, Faculty of Science, University of Ngaoundere, Cameroon \\ ${ }^{2}$ Anatomo-Cytopathology Laboratory, Cameroon Evangelical University Institute, Cameroon \\ ${ }^{3}$ Center for Sustainable Health and Development, Garoua, Cameroon \\ ${ }^{4}$ Department of Physiological Sciences and Biochemistry, FMBS, University of Ngaoundere, Cameroon \\ ${ }^{5}$ Department of Biochemistry, Faculty of Science, University of Dschang, Cameroon
}

*Corresponding author: Dr. TAGNE SIMO Richard, PhD, Department of Biomedical Sciences, Faculty of Science, University of Ngaoundere, PO Box 454 Ngaoundere, Cameroon, Tel: 00237-698-61-32 39

\begin{abstract}
Background: Cervical cancer is a public health concern for women in Sub-Saharan Africa, where 34 over 100,000 are diagnosed with cervical cancer and 23 over 100,000 die yearly.
\end{abstract}

Rationale: We evaluated the knowledge and practices of the female population towards the prevention of cervical cancer in the city of Bafoussam, West Cameroon, considering that poor awareness about the disease and its prevention drives its progression in Africa.

Methods: Study participants ( $N=228$ women) were recruited in two District Health Centres in Bafoussam. They were administered a questionnaire aimed at asserting their knowledge about cervical cancer, risk factors and prevention. Subsequently, cervicovaginal smears were screened and gynaecological signs were assessed.

Results: The age of the population was $31.9 \pm 8.6$ years (from 23 to 60). The most represented age group was [2535] $(50.88 \%)$. Only 89 participants $(39.04 \%)$ had heard about cervical cancer, $63(27.63 \%)$ had heard about risk factors with only $13(5.70 \%)$ able to name at least one risk factor. Moreover, 72 participants $(31.58 \%)$ had heard about cervical screening test, $48(21.05 \%)$ were aware about the existence of means of prevention, and only $6(2.63 \%)$ had heard about human papillomavirus (HPV) relationship to cervical cancer or HPV vaccine. An incidence of $07.63 \%$ was obtained. The most common reason reported for not attending cervical cancer screening was ignorance $(68.92 \%)$.
Conclusions: Our data suggest that there is a real need for raising the awareness about cervical cancer and its prevention in the western region of Cameroon.

\section{Keywords}

Awareness, Cervical cancer, Screening, Precancerous lesion

\begin{abstract}
Abbreviations
HPV: Human Papillomavirus; PCL: Precancerous Lesions; IVA/IVL: Visual Inspection Tests; UCC: Uterus Cervical Cancer; SCC: Squamous Cell Carcinoma; H-SIL: HighGrade Squamous Intraepithelial Lesion; L-SIL: Low-Grade Squamous Intraepithelial Lesion
\end{abstract}

\section{Introduction}

Cancer is pathology due to an uncontrolled multiplication of cells in the patient, resulting from the inability of cells to balance cell division by programmed cell death. It disrupts cellular activities that are necessary for the development and maintenance of multicellular organisms, including growth, differentiation, apoptosis and tissue integrity $[1,2]$. The global incidence of cancer was about 14 million new cases per year in 2012, with more than half of the cases in developing countries, and was expected to reach 22 million by 2032, with cancer deaths rising from about 8.2 million to 13 million per year, if the increasing trend was not upset $[3,4]$. Gynae-

Citation: Tagne SR, Tchakounte CK, Sidje LMG, Ferrand J, Kamdje AHN, et al. (2020) Primary and Secondary Prevention of Cervical Cancer at Two District Health Centres in the West Region of Cameroon. Int J Cancer Clin Res 7:136. doi.org/10.23937/2378-3419/1410136

Accepted: April 23, 2020; Published: April 25, 2020

Copyright: (C) 2020 Tagne SR, et al. This is an open-access article distributed under the terms of the Creative Commons Attribution License, which permits unrestricted use, distribution, and reproduction in any medium, provided the original author and source are credited. 
cological cancers account for almost $50 \%$ of all cancers in women, with 2 million new cases diagnosed yearly and 850,000 deaths, of which 273,000 (about 30\%) due to cervical cancer $[5,6]$. In Cameroon, earlier reports suggested that the number of cases was about 25,000 patients, with an annual incidence of 15,000 new cases, an average age of patients at diagnosis of 45 years, and more than $80 \%$ of cases diagnosed at an advanced stage of the disease, leading to deaths within 12 months from diagnosis for most patients $[7,8]$.

Although cervical cancer is the most common cancer among women in Africa (22\% of cancer cases), it is partly preventable in Africa, where it is estimated that infections with human papillomavirus (HPV) cause about 68,000 cases yearly [9], beyond considerations linked to poor health information systems and cancer registry maintenance common to developing countries, which suggest the existence of a probably higher number of cases. Cervical cancer is easily preventable by screening and can be treated when precancerous lesions are detected early [10]. Thus, a very significant reduction could be obtained in a well-organized healthcare system using screening campaigns where standard cervicovaginal (pap) smears or visual inspection tests (IVA/ IVL) could be used for the detection of precancerous lesions (PCL) of the cervix. Screening for precancerous lesions $(\mathrm{PCL})$ and cancerous by the regular performance of the CVS and awareness campaigns reduced markedly the number of cases and deaths due to uterus cervical cancer (UCC) in developed countries $[6,11,12]$.

Considering that in Cameroon systematic awareness and screening campaigns were recommended by early studies in the last decade, with positive attempts from the Ministry of Public Health to raise the awareness of Cameroonians, we assessed the knowledge of women about cervical cancer, its prevention and risk factors in Bafoussam, the largest city of Cameroonian West Region.

\section{Materials and Method}

\section{Participants and ethical considerations}

Asymptomatic ("healthy") women ( $N=228$ ) living in different areas of the city of Bafoussam (West Region, Cameroon) were recruited at local District Health Centres of Djeleng and King place from February to August 2017. A pre-tested self-administered questionnaire was used to assess the knowledge of cervical cancer among four domains relating to etiology and prognosis, risk factors, cervical cancer awareness and screening methods. A gynaecologist and an epidemiologist determined the validity of each question as well as the entire questionnaire. The questionnaire was originally prepared in French after an exhaustive review of the literature and subsequently was translated into the local language. It was pre-tested in 20 adult women in Bafoussam. Afterwards, a health talk focusing on cancer prevention was held at the study site for the general public including all the study participants.

The Ethical Committee of Cameroon Evangelical University Institute and the competent Authorities of the West Region approved and authorized the study. An informed consent was taken from each participant after providing explanation on the importance of the study and on the procedures, including the questionnaire, pap smears, and data usage.

\section{Study design and data collection}

A cross-sectional study with simple random selection of participants was conducted. Women previously diagnosed with cervical cancer were excluded from the study. The data were collected using a questionnaire that identified women's socio-demographic characteristics, their knowledge on cervical cancer, and their practice of screening. The awareness about the risk of cervical cancer was also assessed by questionnaire, and included knowledge about the link between the risk for developing cervical cancer and personal history of cervical cancer, advanced age, null parity, high parity, late age at first pregnancy, early menarche, family history of cervical cancer, early age at first sexual intercourse, HPV infection, alcohol and smoking. Knowledge about the common screening methods was also assessed.

Pap smears were analysed according to the cytopathological 2001 Bethesda System, where: i) Normal cases may include reactive change due to inflammation, fungal infection, and atrophy; and ii) cytological cases of squamous cell carcinoma (SCC), high-grade squamous intraepithelial lesion (H-SIL), atypical squamous cells (ASC) cannot exclude H-SIL, a low-grade squamous intraepithelial lesion (L-SIL), typical squamous cells of undetermined significance (ASC-US).

\section{Statistical analysis}

Data analysis was done using Epi info version 7.2.2.6. With $\mathrm{Chi}^{2}$ test application. Qualitative data were presented as frequency distribution and Fisher's simplification of Black's nuclear grading scheme was used to determine the grade of cancer. Statistical significance was set at $p<0.05$.

\section{Results}

\section{Sociodemographic characteristics of the study par- ticipants}

Table presents the sociodemographic characteristics of the participants of the study. The participants were women between 23 and 60 years old (average: 31.9 \pm 8.6 years). Women with secondary education were the most represented (61.43\%), followed by university graduates $(29.71 \%)$ and women with primary education (8.10\%). Only 2 illiterate women were registered $(0.75 \%)$ (Table 1$)$. Instead, $64.65 \%$ of married women, $32.02 \%$ of single women, and $3.33 \%$ of widows (Table 
Table 1: Socio-demographic characteristics of participants ( $\mathrm{N}$ $=228$ ).

\begin{tabular}{|c|c|c|}
\hline Variables & $\mathbf{N}$ & $\%$ \\
\hline \multicolumn{3}{|l|}{ Age (years) } \\
\hline$<25$ & 18 & 7.89 \\
\hline [25-35] & 116 & 50.88 \\
\hline [35-45] & 59 & 25.88 \\
\hline$>45$ & 35 & 15.35 \\
\hline \multicolumn{3}{|l|}{ Education } \\
\hline Illiterate & 2 & 0.75 \\
\hline Primary & 18 & 8.10 \\
\hline Secondary & 140 & 61.43 \\
\hline University & 68 & 29.71 \\
\hline \multicolumn{3}{|l|}{ Marital status } \\
\hline Single & 73 & 32.02 \\
\hline Married & 147 & 64.65 \\
\hline Widows & 8 & 3.33 \\
\hline \multicolumn{3}{|l|}{ Occupation } \\
\hline Housewives & 89 & 39.00 \\
\hline Employed & 82 & 36.00 \\
\hline Students & 21 & 9.00 \\
\hline Business women & 30 & 13.00 \\
\hline Retired & 7 & 3.00 \\
\hline \multicolumn{3}{|c|}{ Age at first sexual intercourse } \\
\hline$<16$ & 15 & 6.59 \\
\hline [16-20] & 189 & 82.87 \\
\hline [21-25] & 19 & 8.47 \\
\hline$>25$ & 5 & 2.07 \\
\hline \multicolumn{3}{|c|}{ Parity (number of children) } \\
\hline Nulliparous (0) & 43 & 18.94 \\
\hline Primiparous (1) & 29 & 12.79 \\
\hline Pauciparous (2-4) & 111 & 48.86 \\
\hline Multiparous (5-6) & 29 & 12.81 \\
\hline Grand Multiparous ( $\geq 7$ ) & 15 & 6.59 \\
\hline
\end{tabular}

1). Housewives constituted $39.00 \%$ of the population, while $36.00 \%$ were employed women, and $13.00 \%$ were self-employed (business women) (Table 1 ). The average age at first sexual intercourse was $16.79 \pm 2.22$ years with a minimum of 13 years and a maximum of 28 years. Most participants had had their first intercourse between 16 and 20 years old (82.87\%) (Table 1). The average parity was $2.27 \pm 1.95$ children, with $48.86 \%$ of pauciparous (2-4 children), $18.94 \%$ of nulliparous, around $12 \%$ of primiparous and multiparous (5-6 children), and $6.59 \%$ of grand multiparous ( $\geq 7$ ) (Table 1 ).

\section{Awareness about cervical cancer risk factors and prevention}

Cervical cancer awareness and information sources: Table 2 presents the percentages of participants aware about cervical cancer, its risk factors and prevention. Only 89 women over 228 study participants
Table 2: Knowledge about cervical cancer risk factors and prevention.

\begin{tabular}{|l|l|l|}
\hline Variables & N & $\%$ \\
\hline Aware about cervical cancer? & & \\
\hline Yes & 89 & 39.04 \\
\hline No & 139 & 60.96 \\
\hline $\begin{array}{l}\text { Did you hear about the means of } \\
\text { prevention? }\end{array}$ & & \\
\hline Yes & 48 & 21.19 \\
\hline No & 166 & 72.88 \\
\hline They do not exist & 14 & 5.93 \\
\hline Aware about: & & \\
\hline Cervical cancer risk factors & 63 & 27.63 \\
\hline Cervical screening test & 72 & 31.58 \\
\hline Visual inspection with Lugol's iodine (VILI) & 58 & 25.44 \\
\hline Human Papillomavirus or HPV vaccine & 6 & 4.84 \\
\hline Sources of information about cervical cancer & 18 & 20.22 \\
\hline Medical staff & 31 & 34.83 \\
\hline Media & 25 & 28.09 \\
\hline Family/friends/others & 15 & 16.85 \\
\hline Other & & \\
\hline & & \\
\hline
\end{tabular}

(39.04\%) had heard about cervical cancer (precancerous and cancerous cervical lesions) (Table 2). The main sources of information about cervical cancer, risk factors and prevention reported by participants encompassed the media ( $13.60 \%$ of the study population and $34.83 \%$ of the women aware about cervical cancer), family members or friends $(10.96 \%$ of the study population and $28.09 \%$ of the women aware about cervical cancer), against only $7.89 \%$ and $20.22 \%$ (percent of the study population and of the women aware about cervical cancer, respectively) informed by the medical staff (Table 2).

Known risk factors and prevention: Of the 89 women aware about cervical cancer, 63 had heard about risk factors $(27.63 \%$ of the study population and $70.79 \%$ of the women aware about cervical cancer) (Table 2), but only 13 women could name at least one risk factor, that is only $5.70 \%$ of the study population and $20.63 \%$ of the women who had heard about risk factors. All these women reported multiple sexual partners as a risk factor for cervical cancer, but no participant was aware about relationships between cervical cancer and other known risk factors such as early age at first sexual intercourse, early pregnancy, alcohol, or tobacco.

\section{Screening practice and HPV vaccine}

Only 48 women $(21.05 \%$ of the study population and $53.93 \%$ of the women aware about cervical cancer), were aware about the existence of means of prevention, and 7 women where convinced that such means do not exist (Table 2). The latter had received this wrong information from family members and friends. In this study, of the 89 women aware about cervical cancer, 
72 had heard about cervical screening test $31.58 \%$ of the study population and $80.90 \%$ of the women aware about cervical cancer), and 58 had heard about visual inspection with Lugol's iodine (VILI) (25.44\% of the study population and $65.17 \%$ of the women aware about cervical cancer) (Table 2).

Moreover, only 6 women had heard about HPV, HPV vaccine, or were aware about HPV relationship to cervical cancer $(2.63 \%$ of the study population and $9.52 \%$ of the women aware about cervical cancer) (Table 2).

\section{Gynaecological findings}

Cervix appearance: Table 3 presents the gynaecological observations. Cervices with normal macroscopic appearance were observed in 85 participants over 118 screened $(72.03 \%)$, while 25 cervices $(21.19 \%)$ had an

Table 3: Gynaecological profile of participants.

\begin{tabular}{|l|l|l|}
\hline Variables & $\mathbf{N}$ & $\%$ \\
\hline $\begin{array}{l}\text { Macroscopic appearance of the cervix } \\
\text { (N = 118) }\end{array}$ & & \\
\hline Normal & 85 & 72.03 \\
\hline Inflammatory & 25 & 21.19 \\
\hline Bleeding & 6 & 5.08 \\
\hline Ectropion & 1 & 0.85 \\
\hline Nabothian cysts & 1 & 0.85 \\
\hline Vaginal flora (N = 118) & & \\
\hline Normal & 54 & 45.76 \\
\hline Doderlein flora & 37 & 31.36 \\
\hline Mixed flora & 13 & 11.02 \\
\hline Trichomonas & 3 & 2.54 \\
\hline Absent & 10 & 8.47 \\
\hline Mycotic flora & 1 & 0.85 \\
\hline Cytological abnormalities (N = 182) & & \\
\hline Normal & 133 & 73.08 \\
\hline Inflammatory smears & 36 & 19.78 \\
\hline Precancerous cells & 13 & 7.14 \\
\hline
\end{tabular}

Table 4: Reasons for refusal of screening $(N=173)$.

\begin{tabular}{|l|l|l|}
\hline Variables & N & \% \\
\hline Ignorance & 119 & 68.92 \\
\hline Neglect & 35 & 20.45 \\
\hline Fear of pain & 10 & 5.78 \\
\hline Poverty & 8 & 4.68 \\
\hline
\end{tabular}

Table 5: Age and cytological signs.

\begin{tabular}{|l|l|l|l|l|l|l|}
\hline Variables & $<\mathbf{2 1}$ & $\mathbf{[ 2 1} \mathbf{- 3 5}]$ & $\mathbf{[ 3 6} \mathbf{- 4 5}]$ & $\mathbf{7 4 6}$ & $\mathbf{N}$ & $\mathbf{\%}$ \\
\hline Lesions & 0 & 8 & 4 & 1 & 13 & 7.14 \\
\hline$\%$ & 0 & 8.25 & 9.52 & 4.00 & & \\
\hline Normal & 18 & 89 & 38 & 24 & 169 & 92.86 \\
\hline$\%$ & 100 & 91.75 & 90.48 & 96.00 & & \\
\hline Total & 18 & 97 & 42 & 25 & 182 & 100 \\
\hline Z-value & -1.24 & 0.62 & 0.68 & -0.66 & & \\
\hline
\end{tabular}

inflammatory macroscopic appearance, with cervices bleeding on contact during sampling, cervices with Nabothian cysts or with ectropion in the remainder (Table 3).

\section{Vaginal flora and cytology}

During our screening campaign we performed 118 FCV (Endocol and Exocol). All the smears were stained according to the Papanicolaou technique and read under a microscope in order to establish a report. We organized the results according to the type of flora, inflammation and precancerous lesions. We observed normal flora in $45.76 \%$ of participants, Doderlein flora in $31.35 \%$, as well as flora invaded by Trichomonas (2.54\%), mycotic $(0.85 \%)$ or absent $(8.47 \%)$ (Table 3$)$.

Instead, 133 women over 182 screened (73.08\%) presented without cytological abnormalities, while inflammatory smears were observed in 36 women (19.78\%) and precancerous cells in 13 (7.14\%) (Table 3). Precancerous lesions were observed in 9 participants $(7.63 \%, \mathrm{Cl} 95=$ 2.8-12.4\%), with low-grade intraepithelial lesions in 7 women and squamous atypia of unknown significance in 2.

\section{Reasons for not being screened before}

In this study, only 4 of the women who accepted to be screened had been screened for cervical cancer before, including 2 at the request of a doctor and 2 spontaneously during screening campaigns. Table 4 summarizes the reasons presented by women to justify why they never went for cervical cancer screening in the past. The most common reason reported was ignorance $(68.92 \%)$, followed by neglect $(20.45 \%)$. Poverty was only reported by 8 women (4.68\%) (Table 4).

\section{Risk factors and cytological abnormalities}

Age: Table 5 presents the frequency of the cytological signs observed according to age groups. Of the 13 women with cytological abnormalities, 8 were between 21 and 35 years old $(8.25 \%$ of the age group and $61.54 \%$ of women with cytological abnormalities), 4 were between 36 and 45 (9.52\% of the age group and $30.77 \%$ of women with cytological abnormalities), one was older than 46 (4.00\% of the age group and $7.69 \%$ of women with cytological abnormalities), and none was younger than 21 (Table 5). Due to the small statistical power (N $=13$ ), no statistically significant inter-group difference was observed.

Marital status: Table 6 presents the frequency of the cytological signs observed according to the marital status. Of the 13 women with cytological abnormalities, 10 were married $(8.85 \%$ of the married women and 76 . $92 \%$ of women with cytological abnormalities), and 3 were single $(4.69 \%$ of the single and $23.08 \%$ of women with cytological abnormalities) (Table 6). As for age groups, no statistically significant inter-group difference was observed due to the small statistical power $(\mathrm{N}=13)$. 
Table 6: Marital status and cytological signs.

\begin{tabular}{|l|l|l|l|l|l|}
\hline Variables & Single & Married & Widow & $\mathbf{N}$ & $\%$ \\
\hline Lesions & 3 & 10 & 0 & 13 & 7.14 \\
\hline$\%$ & 4.69 & 8.85 & 0 & & \\
\hline Normal & 61 & 103 & 5 & 169 & 92.86 \\
\hline$\%$ & 95.31 & 91.15 & 100 & & \\
\hline Total & 64 & 113 & 5 & 182 & 100 \\
\hline Z-value & -0.95 & 1.14 & -0.63 & & \\
\hline
\end{tabular}

Table 7: Age at first intercourse and cytological signs.

\begin{tabular}{|l|l|l|l|l|l|l|}
\hline Variables & $<\mathbf{1 6}$ & {$[\mathbf{1 6}-\mathbf{2 0}]$} & {$[\mathbf{2 1} \mathbf{- 2 5}]$} & $\mathbf{>} \mathbf{2 5}$ & $\mathbf{N}$ & $\mathbf{\%}$ \\
\hline Lesions & 2 & 10 & 1 & 0 & 13 & 7.14 \\
\hline$\%$ & 16.67 & 6.54 & 6.67 & 0 & & \\
\hline Normal & 10 & 143 & 14 & 2 & 169 & 92.86 \\
\hline$\%$ & 83.33 & 93.46 & 93.33 & 100 & & \\
\hline Total & 12 & 153 & 15 & 2 & 182 & 100 \\
\hline Z-value & 1.33 & -0.73 & -0.07 & -0.39 & & \\
\hline
\end{tabular}

Age at first intercourse: Table 7 presents the frequency of the cytological signs observed according to the age at first intercourse. About $84.07 \%$ of participants had their first sexual intercourse between 16 and 20 -years-old, $6.59 \%$ before 16 , and $9.34 \%$ after 20 (Table 7). Of the 13 women with cytological abnormalities, 12 had their first intercourse before 21 (7.27\% of the women that had their first intercourse before 21 and 92.73\% of women with cytological abnormalities) (Table 7). As for the other parameters, no statistically significant inter-group difference was observed due to the small statistical power $(\mathrm{N}=13)$.

\section{Discussion}

The observations of the present study suggest that cervical cancer awareness is very low in Bafoussam, the largest city of Cameroonian West Region. In this study, only 89 over 228 participants (39.04\%) were aware of the existence of cervical cancer, against $23-28 \%$ in earlier studies performed in densely populated areas of other regions of the country, including in the Centre Region [7], in the South West Region [7], and in the Northern Regions $[13,14]$. Unfortunately, the quality of the knowledge about cervical cancer was still poor, with only 63 participants $(27.63 \%)$ who had heard about risk factors, 13 who could name at least one $(5.70 \%)$, and none aware about relationships between cervical cancer and other known risk factors such as early age at first sexual intercourse, early pregnancy, alcohol, or tobacco. Moreover, as also reported in the aforementioned studies performed in Cameroon, the main sources of information about cervical cancer (lesions, risk factors and prevention) of the general population were the media $(13.60 \%)$ and family members or friends $(10.96 \%)$, with only $7.89 \%$ informed by the medical staff. Altogether, these findings suggest that Government mediatic campaigns performed in the last decade in Cameroon prob- ably raised the awareness about cervical cancer among the general population, including in Bafoussam, but did not provide good knowledge on cervical cancer and risk factors.

Similarly, few study participants were aware about cervical cancer prevention. Only 48 women $(21.05 \%)$ were aware about the existence of means of prevention, while 7 women where convinced that such means do not exist, due to wrong information from family members and friends. In addition, considering that screening for cervical cancer remains the best way to prevent this pathology, mainly either by visual inspection with Lugol's iodine (VILI) or by cervical screening test [12,15], we assessed the awareness about these screening tools. Only 58 participants had heard about VILI $(25.44 \%)$ and 72 (31.58\%) about cervical screening test. In addition, only 6 women $(2.63 \%)$ had heard about HPV or HPV vaccine, the primary way to prevent precancerous and cancerous lesions of the cervix [16]. Moreover, only 4 women $(4.49 \%)$ had been screened for cervical cancer before, including 2 at the request of a doctor and 2 spontaneously during screening campaigns. Reasons for not being screening before encompassed ignorance (68.92\%), neglect (20.45\%), fear of pain (5.78\%), and poverty $(4.68 \%)$. Similar observations were reported in previous studies performed in Cameroon $[8,7,13]$, in surrounding countries $[17,18]$, and in other developing countries $[19,20]$. The fear of pain and the cost of screening were the most reported reasons limiting cervical cancer screening. The direct consequence of the low practice of cervical cancer screening is an increase in the incidence of precancerous and cancerous lesions of the cervix, contrary to what is observed in developed countries $[3,10,21,22]$. Interestingly, most participants (79.82\%) accepted to be screened.

In our study, we obtained an incidence of $7.14 \%$, with $77.8 \%$ of low-grade intraepithelial lesions and $22.2 \%$ of squamous atypia of unknown significance. Comparable findings were also reported in previous studies in Cameroun, with incidence of precancerous lesions around $7.9 \%[7,8]$. The protective factors observed in our study population were education $(91.14 \%$ with at least a secondary education), age at first sexual intercourse beyond adolescence $193.41 \%$ had their first intercourse after $16[23,24]$. Alarmingly, considering that the age recommended for participation to screening is between 25 and 65 -years-old $[18,25]$, precancerous lesions were reported in many asymptomatic participants under 25 in previous studies in Cameroon $[13,26]$. Similarly, in our study 2 participants with precancerous lesions over 13 where younger than 25 .

Tremendous efforts are being engaged to have national educational campaigns about every 3 years to raise the awareness about cervical cancer and its two main prevention strategies, namely primary prevention by HPV vaccination and secondary prevention by cervi- 
cal cancer screening. However, instead, national screening campaigns are not performed yet and the system relies on patients coming for screening at their expense. In this study it appears that opportunistic screening may have significantly reduce the rates of cervical cancer, but not to the levels seen with organized programs. It is well established that opportunistic screenings underestimate the low socio-economic groups and minorities, but not high-income and well-educated groups, creating a bias in the available data. Thus, this results in the inability for public health decision makers to come up with strategies helping all the segments of the population. Moreover, our study also revealed that the major obstacles for the implementation of these promising tools in Bafoussam were their cost that is high for poor rural populations, and awareness about the importance of screening. Thus, the Cameroonian Health Authorities should find a way to make cervical cancer prevention strategies affordable to all the segments of the population.

\section{Conclusion}

Through the determination of the level of knowledge of women about cervical cancer, the achievement of Screening for CVS in these women and looking for factors associated with prevalence, we can say that women have low knowledge about precancerous lesions and methods of prevention of the cervical cancer. There is a real need for public awareness of cervical cancer in the western region of Cameroon to decrease the incidence of this disease.

In addition, the Cameroonian system still relies on opportunistic screening, where people willing come for screening at their expense, thus, excluding the poor segments of the population. The Cameroonian Health Authorities therefore promote national screening programs and make cervical cancer prevention strategies affordable to all the population.

\section{Acknowledgements}

Authors thank the authorities of Cameroonian West Region and the health professionals of District Health Centres of Djeleng and King Palace for their help in data collection.

\section{Funding Statement}

The present study was partly funded by the Department of Biomedical Sciences, Faculty of Science, University of Ngaoundere, Cameroon.

\section{Conflict of Interest Disclosure}

Authors declare no conflicting financial interest.

\section{References}

1. Jt Cox (2006) The development of cervical cancer and its precursors: what is the role of human papillomavirus infection? Curr Opin Obstet Gynecol 1: s5-s13.
2. Vecchio L, Seke Etet PF, Kipanyula MJ, Krampera M, Nwabo Kamdje $\mathrm{AH}$ (2013) Importance of epigenetic changes in cancer etiology, pathogenesis, clinical profiling, and treatment: what can be learned from hematologic malignancies? Biochim Biophys Acta 1836: 90-104.

3. Bray F, Ren J-S, Masuyer E, Ferlay J (2013) Global estimates of cancer prevalence for 27 sites in the adult population in 2008. Int J Cancer 132: 1133-1145.

4. Cortes J, Perez-García JM, Llombart-Cussac A, Curigliano G, El Saghir NS, et al. (2020) Enhancing global access to cancer medicines. CA Cancer J Clin 72: 105-124.

5. Chrysostomou AC, Stylianou DC, Constantinidou A, Kostrikis LG (2018) Cervical Cancer Screening Programs in Europe: The Transition Towards HPV Vaccination and Population-Based HPV Testing. Viruses 10.

6. de Martel C, Georges D, Bray F, Ferlay J, Clifford GM (2019) Global burden of cancer attributable to infections in 2018: a worldwide incidence analysis. Lancet Glob Health 17.

7. Orock GE, Tchounzou R, Obinchemti TE, Ekane GEH, Nkwele GM, et al. (2015) Pap Smear Screening, the Way Forward for Prevention of Cervical Cancer? A Community Based Study in the Buea Health District, Cameroon. Open Journal of Obstetrics and Gynecology 5: 720-726.

8. Tebeu PM, Major AL, Rapiti E, Petignat P, Bouchardy C, et al. (2008) The attitude and knowledge of cervical cancer by Cameroonian women; A clinical survey conducted in Maroua, the capital of Far North Province of Cameroon. Int $J$ Gynecol Cancer 18: 761-765.

9. Arbyn M, Xu L, Simoens C, Martin-Hirsch PP (2018) Prophylactic vaccination against human papillomaviruses to prevent cervical cancer and its precursors. Cochrane Database Syst Rev 5: CD009069.

10. Driscoll SD, Tappen RM, Newman D, Voege-Harvey K (2018) Accuracy of visual inspection performed by community health workers in cervical cancer screening. Int $J$ Gynaecol Obstet 142: 260-269.

11. Ferlay J, Colombet M, Soerjomataram I, Mathers C, Parkin DM, et al. (2019) Estimating the global cancer incidence and mortality in 2018: GLOBOCAN sources and methods. Int J Cancer 144: 1941-1953.

12. Giorgi Rossi $P$, Camilloni L, Cogo C, Federici A, Ferroni $E$, et al. (2012) Methods to increase participation in cancer screening programmes. Epidemiol Prev 36: 1-104.

13. Kalgong G, Kamdje AHN, Richard TS, Nangue C (2017) Sensitivity and Specificity of Visual Inspection with Acetic Acid (VIA) and with Lugol lodine (VILI) in the Diagnosis of Cervical Cancer in the Northern Region of Cameroon. Int Biol Biomed J 3: 7.

14. Tebeu PM, Petignat $P$, Mhawech-Fauceglia $P$ (2009) Gynecological malignancies in Maroua, Cameroon. Int J Gynaecol Obstet 104: 148-149.

15. Krings A, Dunyo P, Pesic A, Tetteh S, Hansen B, et al. (2019) Characterization of Human Papillomavirus prevalence and risk factors to guide cervical cancer screening in the North Tongu District, Ghana. PLoS One 14: e0218762.

16. Clifford GM, de Vuyst H, Tenet V, Plummer M, Tully S, (2016) Effect of HIV Infection on Human Papillomavirus Types Causing Invasive Cervical Cancer in Africa. J Acquir Immune Defic Syndr 73: 332-339.

17. Assoumou SZ, Mabika BM, Mbiguino AN, Mouallif M, Khattabi $A,(2015)$ Awareness and knowledge regarding of cer- 
vical cancer, Pap smear screening and human papillomavirus infection in Gabonese women. BMC Womens Health 15: 37 .

18. Hweissa NA, Lim JNW, Su TT (2016) Health-care providers' perceptions, attitudes towards and recommendation practice of cervical cancer screening. Eur J Cancer Care 25: 864-870.

19. Almonte M, Ferreccio C, Winkler JL, Cuzick J, Tsu V, et al. (2007) Cervical screening by visual inspection, HPV testing, liquid-based and conventional cytology in Amazonian Peru. Int J Cancer 121: 796-802.

20. Kietpeerakool C, Phianmongkhol Y, Jitvatcharanun K, Siriratwatakul U, Srisomboon J (2009) Knowledge, awareness, and attitudes of female sex workers toward HPV infection, cervical cancer, and cervical smears in Thailand. Int J Gynaecol Obstet 107: 216-219.

21. Fidler-Benaoudia MM, Torre LA, Bray F, Ferlay J, Jemal A (2020) Lung cancer incidence in young women vs. young men: A systematic analysis in 40 countries. Int $\mathrm{J}$ Cancer 5 .
22. Huy NVQ, Tam LM, Tram NVQ, Thuan DC, Vinh TQ, et al. (2018) The value of visual inspection with acetic acid and Pap smear in cervical cancer screening program in low resource settings-A population-based study. Gynecol Oncol Rep 24: 18-20.

23. Lara LAS, Abdo CHN (2016) Age at Time of Initial Sexual Intercourse and Health of Adolescent Girls. J Pediatr Adolesc Gynecol 29: 417-423.

24. Plummer M, Peto J, Franceschi S (2012) Time since first sexual intercourse and the risk of cervical cancer. Int J Cancer 130: 2638-2644.

25. Santesso N, Mustafa RA, Schünemann HJ, Arbyn M, Blumenthal PD, et al. (2016) World Health Organization Guidelines for treatment of cervical intraepithelial neoplasia 2-3 and screen-and-treat strategies to prevent cervical cancer. Int J Gynaecol Obstet 132: 252-258.

26. Nkegoum B, Belley Priso E, Mbakop A, Gwent Bell E (2001) Precancerous lesions of the uterine cervix in cameroonian women. Cytological and epidemiological aspects of 946 cases. Gynecol Obstet Fertil 29: 15-20. 